\title{
Can atlas spina bifida-occulta be a cause of cervicogenic headaches?
}

\author{
Amégninou Mawuko Yao Adigo 1* , Lama Kegdigoma Agoda-Kousséma², Ignéza Komi Agbotsou³, \\ Kokou Adambounou', Kpalma Duga Bakpatina-Batako', Oni Djagnikpo' and Komlanvi Victor Adjénou ${ }^{1}$
}

\begin{abstract}
Cervicogenic headaches are a nosologic entity recently recognized. In our common practice, we have noticed a relative frequency of the atlas spina-bifida occulta during the brain CT scan realized for headaches without cranio-encephalic causes or any other anomaly of the upper cervical region. The aim of this study was to determine a possible connection between cervicogenic headaches (CEH) and atlas spina-bifida occulta. A 2 years prospective and descriptive study in 20 black patients having an atlas spina-bifida occulta diagnosed with a brain CT scan. The mean age of the patients was $43.17 \pm 18.35$ years (extremes: 24 and 72 years). A light female predominance was noticed (sexratio $=1.5$ ). The frequency of symptomatic spina-bifida was $1.72 \%$ (17 cases). The mean age at onset was 31.84 years. The pain was sub-occipital in 14 cases, occipital in 8 cases, bilateral in 12 cases and unilateral in 5 cases. The mean duration of the attacks was $72 \pm 24 \mathrm{~h}$ and the pain intensity was moderate (16 cases); mean and range were 3.6 and 3-6. The frequency of attacks varied between 1 per 7 months $(n=2)$ and 2 per week $(n=1)$ in those with non-daily headache. One attack per 5-7 weeks was the most commonly occurring attack frequency. The pain was reproduced by the pressure of the occipital region or upper cervical in 15 cases. The mean number of criteria was five and there was a strong positive correlation between criteria and $\mathrm{CEH}\left(\chi^{2}=45.57 ; \mathrm{V}=0.62\right)$. The associated signs were photophobia and nausea in one case each. Indomethacin, Ergotamine and/or Sumatriptan were without any antalgic effect in 16 cases. Pain ceased after an anesthetic blockade of C2 (16 cases). The results show that atlas spina-bifida occulta is not involved in CEH pure form genesis. On a small sample, the atlas spina-bifida seems to be a cause of CEH associated with headache and disorders of the neck.
\end{abstract}

Keywords: Spina-bifida occulta, Atlas, Cervicogenic headaches, Africa

\section{Background}

Cervicogenic headaches $(\mathrm{CEH})$ are a nosologic entity recently recognized (Sjastaad et al. 1983). They were rare and their diagnostic calls upon anamnestic, clinic and radiologic criteria (Antonaci et al. 2006; Bogduk and Govind 2009). They have numerous causes and comprise the cervico-occipital hinge malformations (Olesen and Steiner 2004). Spinabifida occulta is a defect of closure of the posterior arc of a vertebra without an individualized paravertebral mass.

In our common practice, we have noticed a relative frequency of the atlas spina-bifida occulta during the brain CT scan realized for headaches without cranio-encephalic

\footnotetext{
*Correspondence: landry05@gmail.com

1 Radiology Department of Campus Teaching Hospital of Lome, PO Box: 4308, Lome, Togo

Full list of author information is available at the end of the article
}

causes or any other anomaly of the upper cervical region. But, to our knowledge, no study has established the connection between atlas spina-bifida occulta and headaches. This has motivated us to initiate this study which objective was to determine a possible imputability of the headaches to atlas spina-bifida occulta.

\section{Patients and methods}

\section{Study design and instruments}

It was a 2 years transversal prospective monocentric study from June 2012 to 2014 in black patients. Patients of all age and both sex, referred to the Radiology Department for a brain CT scan, having headaches or not and for who an atlas spina-bifida occulta was observed, were included in our study. All the patients had gone through a rapid malaria diagnostic test which was negative in all the

\section{贷 Springer}


cases. We used a General Electric scanner device (bright speed 16 barrettes). Helical acquisitions were made with and without contrast product. The analysis was made in parenchymatous and bone windows one after the other by two radiologists. There was no discordance and the two radiologists agreed on the normality of the brain $\mathrm{CT}$ scan and the upper cervical region except the presence of atlas spina-bifida occulta in all the cases.

We raised as starting hypothesis: can atlas spina-bifida occulta be a cause of CEH?

During the study, we called the patients who presented a spina-bifida to precise the characteristics of the pain according to CEH criteria (Antonaci and Sjaastad 2011; Sjaastad 2008; Sjaastad and Bakketeig 2008; Fredriksen et al. 2015) without anesthetic blockades. The external digital pressure is exerted with the thumb, at a $90^{\circ}$ angle with the skin. Pain intensity was appreciated with the visual analog scale (VAS) and related by Fig. 1 (Dixit

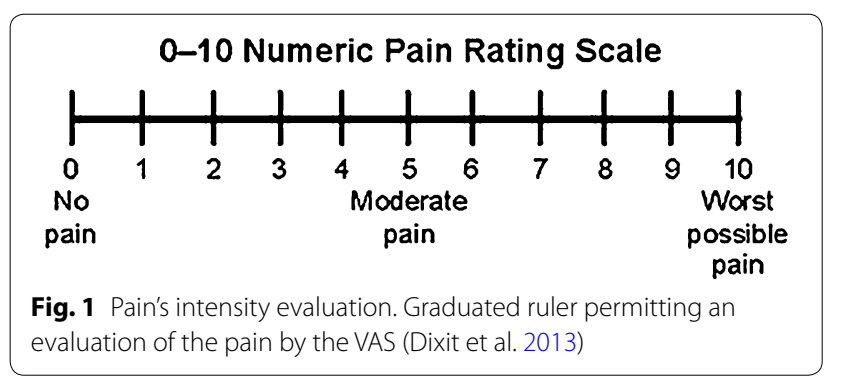

et al. 2013). The correspondence between VAS level and pain's intensity was as follow: from 0 to 3 (low pain); from 3 to 5 (moderated pain); from 5 to 7 (intense pain) et $>7$ (extremely intense pain).

\section{Statistical analyses}

Qualitative data were treated with Microsoft Word 2007 and with Microsoft Excel 2007. Statistical analyses were performed using $\mathrm{R}$ Core Team (2013). The results were tested by Fisher exact test, $\chi^{2}$ test and Cramer V test. Every difference inferior to 0.05 was considered as significant.

\section{Results}

\section{Patients' trends}

Nine hundred and ninety (990) patients were referred in the Radiology Department during the study period. Twenty patients have presented an atlas spina-bifida occulta, 17 were symptomatic, meaning $1.72 \%$ of the brain CT scan realized. Figure 2a, b illustrate the scan aspect of an atlas spina-bifida occulta.

The mean age was $43.17 \pm 18.35$ years with extremes from 24 to 72 years. A light female predominance came out from our study; the sex-ratio was 1.5. We found a notion of cervical trauma in 11 cases. Primary headache in personal or familial record was found only in 4 cases over 17.
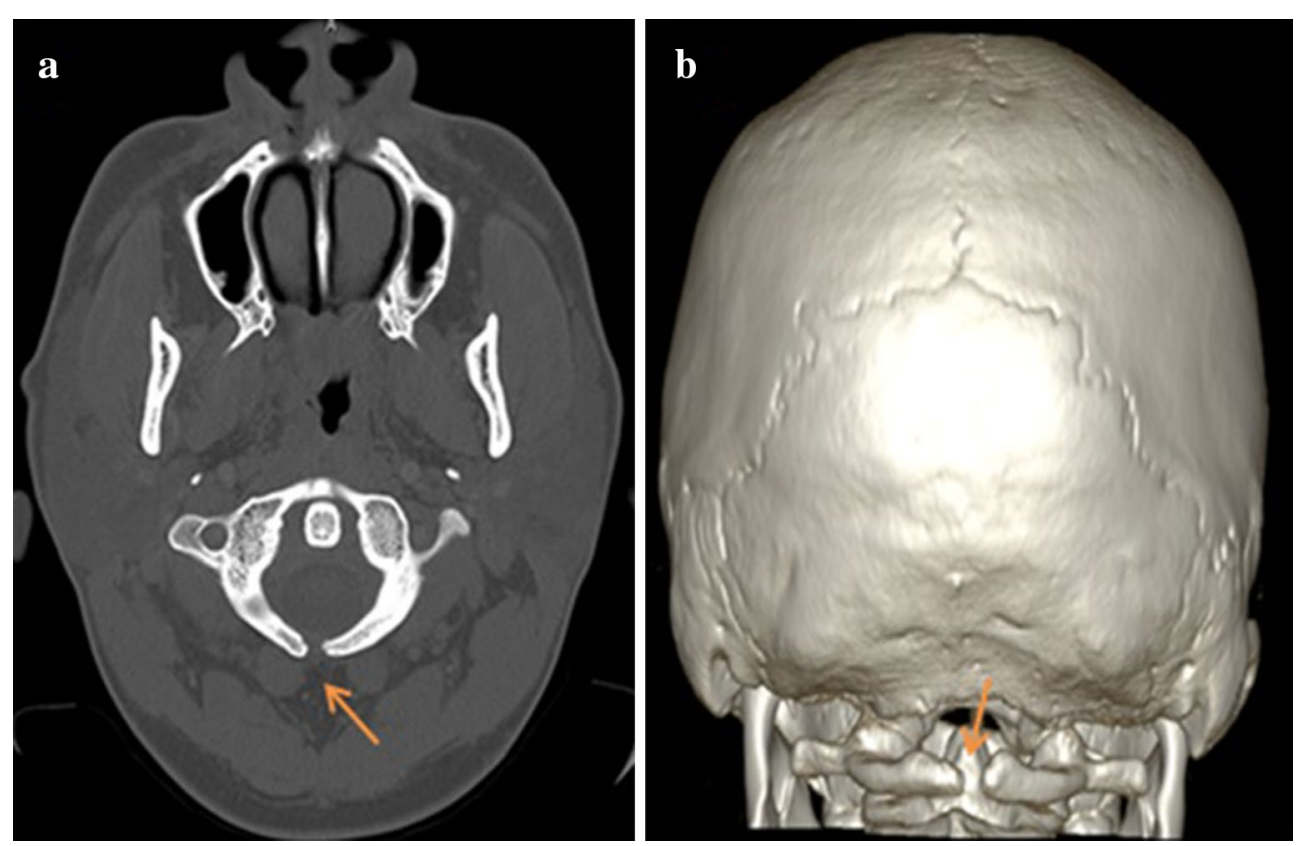

Fig. 2 Atlas spina-bifida. Bone windows CT axial cut (a) with reconstruction VR (b) of an atlas spina-bifida occulta in a patient suffering from headache 


\section{Pain characteristics}

The pain characteristics according to $\mathrm{CEH}$ criteria are summarized in Table 1 . The difference according to the sex, the various parameters of the pain were statistically significant $(\mathrm{p}<0.05)$. The mean number of criteria was 5.29. There was a strong positive correlation between criteria and $\mathrm{CEH}\left(\chi^{2}=45.57 ; \mathrm{V}=0.62\right)$.

The pain was: non-throbbing (16 cases), fluctuating (13 cases) and continuous (4 cases). It was sub-occipital (nape) in 14 cases over 17 , occipital in 8 cases, unilateral in 5 cases and bilateral in 12 cases. The mean age (and range) at onset was $31.84 \pm 7.35$ years (23-47 years). The duration of the attacks is summarized by Fig. 3 (mean $=72 \pm 24 \mathrm{~h}$ ). The pain intensity was moderate (16 cases) or intense (1 case); mean (and range) was 3.6 (3-6). The frequency of attacks varied between 1 per 7 months $(\mathrm{n}=2)$ and 2 per week $(\mathrm{n}=1)$ in those with non-daily headache. One attack per 5-7 weeks was the most commonly occurring attack frequency.

Table 1 The pain characteristics according to cervicogenic headaches criteria

\begin{tabular}{lllc}
\hline & Male (n) & Female (n) & Total (N) \\
\hline $\begin{array}{l}\text { I: Unilateral head pain, without side } \\
\text { shift }\end{array}$ & 3 & 2 & 5 \\
$\begin{array}{l}\text { II: Provocation, unphysiological neck } \\
\text { positions }\end{array}$ & 6 & 8 & 14 \\
$\begin{array}{l}\text { III: Provocation, externally; neck/ } \\
\quad \text { Occipital area }\end{array}$ & 6 & 9 & 15 \\
$\begin{array}{l}\text { IV: Range of motion, neck; deficit* } \\
\text { V: Shoulder pain, diffuse }\end{array}$ & 5 & 8 & 13 \\
$\begin{array}{l}\text { VI: Arm pain, diffuse } \\
\text { VII: Pain, starting posteriorly—ending }\end{array}$ & 7 & 3 & 5 \\
up anteriorly & 1 & 3 & 4 \\
\end{tabular}

* Those with $15^{\circ}$ rotation deficit

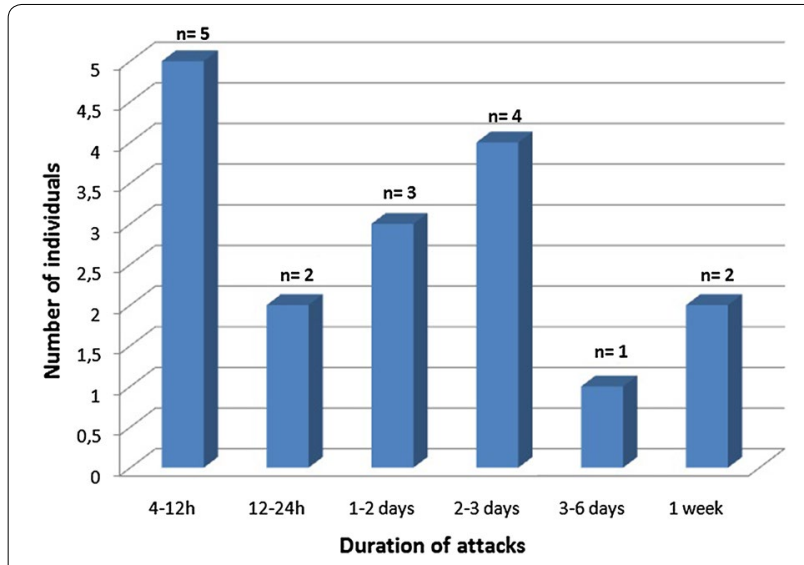

Fig. 3 Distribution of the individuals according to the duration of the attacks
The pressure of the occipital or upper cervical region reproduced the pain in 15 cases over 17 (Table 2). The trigging factors were: inclination of the nape (11 cases) and ante-flexion (14 cases). Cough (10 cases), sneezing ( 8 cases) and effort (10 cases) were the aggravating factors. The associated signs were photophobia and nausea in one case each. There was no phonophobia, vomiting or periorbital edema.

Indomethacin, Ergotamine and/or Sumatriptan were without any antalgic effect in 16 cases. Pain regressed after an anesthetic blockades of C2 (16 cases) and spontaneously for one case.

\section{Discussion}

\section{Prevalence and patients' trends}

The prevalence of CEH was $1.72 \%$ of the brain scanner performed during the study period. This result is lightly inferior to the one (2.2\%) found by Sjaastad and Bakketeig (2008). The difference between both values could be explained by the fact that Sjaastad and Bakketeig (2008) had studied various etiologies of $\mathrm{CEH}$ whereas we got focused on the relation between $\mathrm{CEH}$ and atlas spinabifida occulta.

The elements in favor are first of all age and sex. The symptoms started at the middle-age of $31.84 \pm 7.35$ years. This result corroborates Sjaastad and Bakketeig (2008); Haldeman and Dagenais (2001) studies who have found a middle-age of 33-43 years. The female predominance observed (sex-ratio: 1.5) was evocative of the diagnostic. In the Vågå study (Sjaastad and Bakketeig 2008), there seemed to be a certain male preponderance (female/male: 0.71 ). In a hospital-based series, however, a female preponderance (2.0-7.2) has been observed (Sjastaad et al. 1983; Sjaastad and Fredriksen 2002). This marked variation has its explanation-a relatively mild CEH form, not leading to consultations, seems to prevail in the population at large. Those consulting physicians are mainly female. In the Vågå study, males, generally, and to a high degree those with $\mathrm{CEH}$, tended to come for an appointment in the final phase. If the study had been interrupted

Table 2 Hypersensitive areas of the neck

\begin{tabular}{|c|c|c|c|}
\hline & Male (n) & Female (n) & Total $(\mathrm{N})$ \\
\hline Groove behind mastoid process & 3 & 4 & 7 \\
\hline GON/MON & 2 & 4 & 6 \\
\hline Transverse processes, $\mathrm{C} 4 / \mathrm{C} 5$ & 2 & 2 & 4 \\
\hline $\begin{array}{l}\text { Tendon insertions, along bony ridge: } \\
\text { protuberantia occipitalis externa, } \\
\text { mastoid process }\end{array}$ & 4 & 5 & 9 \\
\hline $\begin{array}{l}\text { Upper part sternocleidomastoid } \\
\text { musclea }\end{array}$ & 4 & 7 & 11 \\
\hline
\end{tabular}


at an earlier stage than at $88.6 \%$, there would have been a female preponderance also in the Våga study (Sjaastad and Bakketeig 2008). So, Sjaastad and Bakketeig (2008) thought that the passage in the criteria describing the female sex as a characteristic trait should be deleted.

\section{Pain characteristics}

\section{Arguments in favour of the cervicogenic origin}

Localization of initial pain was occipital (8/17 cases) and sub-occipital (14/17 cases) with a postero-anterior irradiation in all cases. In fact, the postero-anterior irradiation of the pain could be an important criterion in the diagnostic of CEH according to Fredriksen et al. (2015), International Headache Society (IHS) (2013).

In the majority of the cases, the trigging factors as the inclination of the nape (11/17 cases), ante-flexion $(14 / 17$ cases) and the pressure of the occipital or upper cervical region (15/17 cases) were observed. They could allow eliminating in a certain extent a tension headache as an origin of those pains, according to IHS criteria (2013). Digital pressure (i.e., 3-4 kg) directly applied against certain neck structures seems to discriminate fairly well between patients and healthy individuals (Sjaastad and Bakketeig 2008; Sjaastad et al. 2003). A clearly positive test on the symptomatic side is a relatively strong signal for $\mathrm{CEH}$. In the absence of a positive test, at this stage of development, it is hard to establish a CEH diagnosis.

Some elements of our study could allow eliminating migraine attack and tension headache (International Headache Society (IHS) 2013; Antonaci et al. 2006). Those elements were the absence of primary headache in personal or family record, nausea, vomiting and phono/ photophobia in the majority of the cases, and the tonality and quality of the headaches (Antonaci et al. 2006; Haldeman and Dagenais 2001). To all this, we can add the absence of pain remission with Indomethacin, Ergotamin and/or Sumatriptan. Chronic paroxysmal hemicrania is easily distinguished from $\mathrm{CEH}$ by the following: its absolute response to moderate indomethacin dosages, its relatively short duration, its excessively severe attacks, and its marked autonomic signs (e.g., ipsilateral lacrimation and conjunctival injection) (Sjaastad and Dale 1976).

The mean duration of the attacks was $72 \pm 24 \mathrm{~h}$ and the pain intensity mean (and range) was 3.6 (3-6). These results corroborate the one found by Sjaastad and Bakketeig (2008) who found a duration superior to $72 \mathrm{~h}$ in $61 \%$ of the cases. The mean intensity (and range) of the pain was equal to 3.8 (and 3-5) in Våga study (Sjaastad and Bakketeig 2008). This mean intensity is lower and bigger than what is observed in migraine without aura (4.2) and tension headaches (3.1); respectively (Sjaastad and Bakketeig 2008). Pain was chronic in all our patients such as in the "Core" group of Sjaastad and Bakketeig (2008).

The mean number of criteria was five and there was a strong positive correlation between criteria and $\mathrm{CEH}$ $\left(\chi^{2}=45.57 ; \mathrm{V}=0.62\right)$. This mean number of criteria was inferior to Sjaastad and Bakketeig (2008) who found six (6). According to Fredriksen et al. (2015), the five items of IHS (three criteria and two comments) can permit the diagnosis of $\mathrm{CEH}$. Among those five items was the unilaterality of the pain which was the first criterion. This strong correlation coefficient of Cramer shows that there exists a cervicogenic factor in headache genesis in our patients.

The anesthetic blockades of $\mathrm{C} 2$ aims diagnostic and therapeutic. It could be a major criterion in the diagnostic of the CEH (Sjastaad et al. 1983; Sjaastad and Bakketeig 2008; Fredriksen et al. 2015; Haldeman and Dagenais 2001; International Headache Society (IHS) 2013; Antonaci et al. 2006). In our study, the quasi-totality of the patients (16/17 cases) had a pain remission after anesthetic blockades of $\mathrm{C} 2$. However, the confirmation by anesthetic blockade of $\mathrm{C} 2$ or of the greater occipital nerve does not seem specific and are not obligatory in routine work. In fact, Caputi and Firetto (1997) report a significant improvement of $85 \%$ of 23 patients suffering from migraine by anesthetic blockades of the greater occipital nerve.

\section{Arguments in disfavor of the cervicogenic origin}

Regarding all these arguments evocating a cervicogenic origin of secondary headaches to an atlas spina-bifida occulta, the first unfavorable element was the bilaterality of the pain in the majority of the cases (12/17 cases). In fact, many authors sustain the unilaterality of the pain in the CEH (Sjaastad and Bakketeig 2008; Fredriksen et al. 2015; International Headache Society (IHS) 2013; Antonaci et al. 2006; Caputi and Firetto 1997; Antonaci et al. 2001). Therefore, the frequent bilaterality of the headaches cannot be attributed to a cervicogenic origin and this despite the aggravating circumstances and the positivity of the anesthetic blockade of $\mathrm{C} 2$. In the Vaga study, cases presenting with $<6$ criteria and $\geq 4$ criteria were also grouped together; varying criteria combinations were considered as acceptable evidence for $\mathrm{CEH}$, but unilaterality would still be a demand (Sjaastad and Bakketeig 2008). The great majority of bilaterality found in our study, despite the strong correlation between the criteria and $\mathrm{CEH}$, suggest the existence of another associated factor.

The second argument in disfavor is the small number of diffuse pain of the shoulder and the arm, mean respectively in 4 and 5 cases. Those values are clearly inferior to those observed by Sjaastad and Bakketeig (2008) who 
found $100 \%$ of the cases for each localization (shoulder and arm).

\section{Synthesis of the results}

These results on a small sample do not seem to involve the atlas spina-bifida occulta in the genesis of $\mathrm{CEH}$ pure form. So, the spina-bifida is, probably, a source of $\ll \mathrm{CEH}$ associated with headache and disorders of the neck». But could we formally eliminate headaches associated to a cervical rachis disorder pure form? Is the sample sufficient? Perhaps it would be necessary to lead a multicentric study allowing recruiting a greater number of patients, and why not of different races, to confirm the results of this study.

\section{Conclusion}

We thought it would be simple to say that atlas spinabifida was a source of CEH. We have not found an indisputable connection between spina-bifida occulta of atlas and $\mathrm{CEH}$ pure form. Any patient who could have given us this hope was contradicted with the two following. On a small sample, the atlas spina-bifida seems to be a cause of $\mathrm{CEH}$ associated with headache and disorders of the neck. A multicentric study on a greater number of patients would allow, maybe, to reinforce the starting hypothesis or eventually to confirm a mixed form.

\section{Abbreviations}

CEH: cervicogenic headaches; IHS: International Headache Society; VAS: visual analog scale.

\section{Authors' contributions}

All authors have contributed to the conception and design of the manuscript and to the acquisition, analysis and interpretation of the data; they have been involved in drafting and revising the manuscript. All authors read and approved the final manuscript.

\section{Author details}

${ }^{1}$ Radiology Department of Campus Teaching Hospital of Lome, PO Box: 4308 Lome, Togo. ${ }^{2}$ Radiology Department of Sylvanus Olympio Teaching Hospital of Lome, Lome, Togo. ${ }^{3}$ Neurology Department of Campus Teaching Hospital of Lome, Lome, Togo.

\section{Competing interests}

The authors declare that they have no competing interests.

Received: 20 August 2015 Accepted: 5 October 2015

Published online: 13 October 2015

\section{References}

Antonaci F, Sjaastad O (2011) Cervicogenic headache: a real headache. Curr Neurol Neurosci 11:149-155

Antonaci F, Ghirmai S, Bono G, Sandrini G, Nappi G (2001) Cervicogenic headache: evaluation of the original diagnostic criteria. Cephalalgia 21(5):573-583

Antonaci F, Bono G, Chimento P (2006) Diagnosing cervicogenic headache. J Headache Pain 7:145-148

Bogduk N, Govind J (2009) Cervicogenic headache: an assessment of the evidence on clinical diagnosis, invasive tests, and treatment. Lancet Neurol 8(10):959-968

Caputi C, Firetto V (1997) Therapeutic blockade of greater occipital and supraorbital nerves in migraine patients. Headache 37:174-179

Dixit V, Dixit M, Hegde V, Sathe S, Jadhav S (2013) Clinical evaluation of conventional and laser tooth preparation using visual analogue scale. J Dent Laser 1(7):27-29

Fredriksen TA, Antonaci F, Sjaastad O (2015) Cervicogenic headache: too important to be left un-diagnosed. J Headache Pain 16:6

Haldeman S, Dagenais S (2001) Cervicogenic headaches: a critical review. Spine J 1:31-46

International Headache Society (IHS) (2013) The international classification of head-ache disorders, 3rd edition (beta version). Cephalalgia 33(9):629-808

Olesen J, Steiner TJ (2004) The international classification of headache disorders, 2nd edn (ICDH-II). Cephalalgia 75:807-808

R Core Team (2013) R: A language and environment for statistical computing. R foundation for statistical computing, Vienna, Austria. http://www.Rproject.org/. Accessed 13 Sept 2014

Sjaastad O (2008) Cervicogenic headache: comparison with migraine without aura. Vågå study. Cephalalgia 28(Suppl 1):18-20

Sjaastad O, Bakketeig L (2008) Prevalence of cervicogenic headache. Vågå study of headache epidemiology. Acta Neurol Scand 117:173-180

Sjaastad O, Dale I (1976) A new (?) clinical headache entity; "chronic paroxysmal hemicrania" 2. Acta Neurol Scand 54:140-159

Sjaastad O, Fredriksen TA (2002) Cervicogenic headache: the importance of sticking to the criteria. Funct Neurol 17:35-36

Sjaastad O, Fredriksen TA, Petersen HC, Bakketeig LS (2003) Features indicative of cervical abnormality. A factor to be reckoned with in clinical headache work and research? Funct Neurol 18:195-203

Sjastaad O, Saunte C, Hovdahl H, Breivik H, Gronbaek E (1983) Cervicogenic headache: an hypothesis. Cephalalgia 3:249-256

\section{Submit your manuscript to a SpringerOpen ${ }^{\circ}$ journal and benefit from:}

- Convenient online submission

- Rigorous peer review

- Immediate publication on acceptance

- Open access: articles freely available online

- High visibility within the field

- Retaining the copyright to your article

Submit your next manuscript at $>$ springeropen.com 